\title{
APONTAMENTOS GERAIS SOBRE OS PRODUTORES E A PRODUÇÃO DE VERDADE EM ARISTÓTELES
}

\author{
Nazareno Eduardo de Almeida \\ Universidade Federal de Santa Catarina
}

\begin{abstract}
Resumo: Mesmo reconhecido por diversos autores recentes como precursor dos modernos conceitos de produtores de verdade (truthmakers) e de produção de verdade (truthmaking), nenhum tratamento destes conceitos na obra de Aristóteles ainda foi apresentado. 0 presente artigo procura fazer uma apresentação introdutória destes conceitos no pensamento do mestre do Liceu através da análise de algumas passagens retiradas de Categorias e da Metafísica, mostrando que o conceito de produtor de verdade é determinado pela noção de estado de coisas (to pragma) e a relação de produção de verdade por meio dos conceitos de fundação ontológica e de dependência ontológica.
\end{abstract}

Palavras chave: Aristóteles, produtores de verdade, produção de verdade

Abstract: Even recognized by several recent authors as the forerunner of the modern concepts of truthmakers and of truthmaking, no treatment of these concepts in Aristotle's work was until now presented. This article try to make an introductory presentation of these concepts in the thought of the Lyceum master through the analysis of some passages picked out from Categories and Metaphysics, showing that the concept of truthmaker is determined by the notion of state of affair (to pragma) and the truthmaking relation by way of the concepts of ontological grounding and of ontological dependence.

Keywords: Aristotle, Truthmakers, Truthmaking.

\section{INTRODUÇÃO}

A problemática filosófica concernente aos produtores de verdade envolve inicialmente a determinação de três conceitos básicos: que tipo de entidades conta como portador (ou um portador primário) de valores de verdade (truthbearer); que tipo de entidades conta como produtor deste valor 
de verdade (truthmaker) e como se dá a relação de produção de verdade que intercorre entre ambos os tipos de entidades (truthmaking). Apesar de tal problemática só recentemente ter sido estabelecida como tema de debate, já é consenso entre os autores diretamente envolvidos nesta discussão que ela remonta à obra de Aristóteles. ${ }^{1}$

Contudo, nenhum tratamento direto de como tal problemática se apresenta no corpus aristotelicum ainda foi realizado até o momento. Meu objetivo neste artigo é iniciar um tal tratamento por meio de apontamentos bastante gerais, pois um tratamento mais aprofundado demandaria uma extensão muito maior do que a de um artigo. Dado o caráter introdutório, apresentarei apenas algumas passagens chave da obra de Aristóteles (retiradas do tratado Categorias e da Metafísica) em que os conceitos de produtores e produção de verdade são claramente estabelecidos dentro das análises aristotélicas da relação entre pensamento, linguagem e realidade.

\section{A) $O$ SURGIMENTO DOS CONCEITOS DE PRODUTORES E DE PRODUÇÃO DE VERDADE NO TRATADO CATEGORIAS}

$\mathrm{Na}$ literatura atual sobre os produtores de verdade a seguinte passagem é remetida por diversos autores como sendo o lugar primário de surgimento dos conceitos de produtores de verdade e de produção de verdade na obra de Aristóteles. ${ }^{2}$ Encontra-se em Categorias, 12:

"Parece, contudo, que além <dos sentidos〉 enumerados, há
ainda um outro, pois dentre os <itens> que admitem a
conversão segundo a implicação de ser, o causador de ser para
um dos dois, de qualquer modo e com razão, pode ser dito
anterior por natureza. Que há algo assim, é evidente: pois <a
propriedade> 'ser humano' converte-se, segundo a implicação
de ser, em relação ao enunciado verdadeiro acerca dela, pois se
<algo〉 é <um> ser humano, <então> é verdadeiro o
enunciado pelo qual enunciamos que '<isto> é <um> ser
humano', e certamente este converte-se, pois se <é> verdadeiro
o enunciado pelo qual enunciamos que '<isto> é <um> ser

1 Cf. ARMSTRONG, 1997, p. 13; 2004, p. 4; KÜNNE, 2003, p. 150 ss; MERRICKS, 2007, p. 01; SCHAFFER, 2008, p. 11.

${ }^{2} \mathrm{Cf}$. nota 1. 
humano', <então este algo> é <um> ser humano. Porém, de modo algum, o enunciado verdadeiro é causador de ser do estado de coisas [to pragma] 〈referido〉, 〈mas〉, ao contrário, de certo modo parece ser o estado de coisas o causador de ser verdadeiro o enunciado, pois é pelo ser ou não 〈ser> do estado de coisas que o enunciado é dito verdadeiro ou falso.”3

Nesta passagem temos vários conceitos envolvidos. O capítulo como um todo apresenta os vários sentidos de anterior ou primário (proteron). $\mathrm{O}$ trecho em questão explicita um sentido de anterioridade ou prioridade que acontece no âmbito daquelas coisas que, à primeira vista, seriam simultâneas por natureza, ou seja, que aparentemente convertem-se segundo a implicação de ser e, por isso, estariam em uma relação simétrica entre si. O exemplo dado é o da relação entre enunciados verdadeiros e os estados de coisas aos quais se referem. Aparentemente, a relação entre ambos seria uma relação simétrica. O exemplo apresentado na passagem se mostra como uma versão semiformal muito parecida com o famoso esquema $\mathrm{T}$ proposto por Tarski. Assim, o enunciado "Isto é um ser humano" é verdadeiro se, e somente se, isto é um ser humano.

Contudo, se esta relação é simétrica do ponto de vista lógicosemântico, para Aristóteles esta simultaneidade ou simetria não pode ser transposta para o nível ontológico. Isto significa: o ser de um enunciado declarativo (seu ser verdadeiro ou ser falso) não pode ser a causa da existência ou inexistência do estado de coisas; bem antes, é necessariamente a existência ou inexistência do estado de coisas que é a causa do ser verdadeiro ou ser falso do enunciado declarativo. Portanto, do ponto de vista ontológico, o estado de coisas é necessariamente anterior e causador do ser verdadeiro ou ser falso dos enunciados declarativos que podem se referir a este mesmo estado de coisas.

Outra passagem, implicitamente ligada a anterior, que envolve a teoria aristotélica dos produtores e da produção de verdade encontra-se em Categorias, 7, onde Aristóteles apresenta os critérios semânticos e ontológicos para identificar os predicados e as propriedades relativos: ${ }^{3}$ Categorias, 12,14 b 10-22. Todas as traduções dos textos de Aristóteles são do autor do presente artigo. Não
apresento nas notas o texto grego utilizado para manter a brevidade do artigo. 
"Contudo, parece que não é em todos os casos verdadeiro que os <estados de coisas> relativos são simultâneos por natureza, pois o cognoscível [to epistêton] parece ser anterior ao conhecimento [epitêmês], posto que no mais das vezes adquirimos os conhecimentos a partir dos estados de coisas [pragmatôn] que existem previamente [prouparchontôn] <à aquisição do conhecimento>, pois em poucos casos ou em nenhum chegamos a ver algum conhecimento surgido simultaneamente ao que é cognoscível. Além disso, de um lado, destruído o cognoscível, destrói-se o conhecimento <do mesmo>, mas, de outro lado, <destruído> o conhecimento não se destrói <,por isso,> o cognoscível, pois em não havendo o cognoscível, 〈então〉 não há conhecimento - posto que então será conhecimento de coisa nenhuma -; contudo, em não havendo conhecimento, nada impede que haja $o$ cognoscível."

Esta passagem, na realidade, antecipa aquela já citada do capítulo 12 do mesmo tratado. Um dos critérios ontológicos para a identificação de propriedades e estados de coisas relativos é serem estes simultâneos por natureza. A definição de simultâneo por natureza encontra-se justamente no capítulo 13 de Categorias (14 b 27-29) e diz: "simultâneos por natureza são aqueles <itens> que convertem-se segundo a implicação de ser, sem que de nenhum modo um seja causador de ser do outro." Somente os estados de coisas relativos em sentido estrito são simultâneos por natureza. Mas há também relativos que não cumprem esta determinação de todo. $\mathrm{O}$ trecho acima citado mostra justamente que tal é o caso da relação entre conhecimento e cognoscível. Do ponto de vista lógico-semântico, o conhecimento é conhecimento relativamente ao que é cognoscível, tanto quanto o cognoscível é cognoscível relativamente ao conhecimento. Entretanto, esta simultaneidade lógico-semântica não implica em uma simultaneidade ontológica ("por natureza"), pois isso acarretaria, conforme a breve redução ao absurdo exposta no texto, que se não houvesse conhecimento, então não haveria algo cognosćivel. A tese de fundo existente aqui é que o conhecimento (na medida em que todo

\footnotetext{
${ }^{4}$ Categorias, cap. 7, 7 b 22-31. Traduzi aqui o termo 'to epistêton' por 'cognoscível', mas o termo grego também pode ser vertido por 'conhecido'. Em outros momentos do mesmo capítulo este último será mais adequado para a tradução do termo original, mas não me deterei sobre esta variação de sentido do termo.
} 
conhecimento, em sentido estrito, é verdadeiro) só é conhecimento por causa do estado de coisas cognoscível, o qual é ontologicamente anterior ao possível conhecimento sobre o mesmo.

Pouco depois, o mesmo argumento é estendido à relação entre a percepção (aisthêsis) e o perceptível (aisthêton) ${ }^{5}$, argumento este que será novamente usado por Aristóteles em Metafísica, IV, 6, para refutar o relativismo de Protágoras. Destarte, o que torna verdadeiro ou falso o conhecimento é a natureza mesma do estado de coisas cognoscível, bem como o que torna verdadeira ou falsa uma determinada percepção é a natureza mesma do estado de coisas perceptível. Tanto percepções quanto conhecimentos pressupõem crenças que são expressas por meio de enunciados declarativos, de modo que a assimetria entre o ser (verdadeiro ou falso) das declarações e o ser dos estados de coisas é o que está implícito nesta passagem acerca deste tipo diverso de relativos constituídos pelos conhecimentos e percepções. Isto mostra que a teoria aristotélica sobre os produtores e a produção de verdade não se limita, como parecem indicar as remissões dos recentes teóricos sobre estes conceitos, aos aspectos lógicosemânticos do conceito de verdade, mas se estendem aos aspectos epistêmicomentais envolvidos na análise deste mesmo conceito, aspectos estes que, por conseguinte, põem em jogo não apenas temas fundamentais da lógica e da ontologia aristotélicas, mas também de sua filosofia da mente e epistemologia. ${ }^{6}$

\footnotetext{
${ }^{5} \mathrm{~A}$ mesma observação feita sobre o termo 'to epistêton' na nota anterior vale para o termo 'to aisthêton', que pode ser vertido tanto por 'perceptivel' como por 'percebido'.

${ }^{6}$ Mesmo não sendo possível desenvolver este ponto em detalhe neste artigo, é interessante observar que o aspecto epistêmico-mental é geralmente negligenciado nas recentes teorias sobre os produtores e sobre a produção de verdade. Na obra mais vasta e influente sobre o tema, Truth and truthmakers, escrita por David Armstrong, o caráter epistêmico-mental envolvido na problemática é parcamente tratado, não desempenhando um papel decisivo nos argumentos. A teorização de Armstrong, bem como de vários outros autores da discussão, resume-se basicamente à correlação (sem dúvida importante) entre aspectos lógico-semânticos e ontológicos envolvidos em uma concepção correspondencial do conceito de verdade (Cf. ARMSTRONG, 2004, cap. 3). Uma das possíveis contribuições que se podem extrair da teorização aristotélica sobre o tema é justamente a importância do aspecto epistêmico-mental envolvido na correlação de produção de verdade que intercorre entre produtores e portadores de verdade.
} 
Apresentadas sucintamente estas passagens, cabe agora retirar alguns conclusões gerais sobre as mesmas no que tange a como Aristóteles trata aqui os conceitos de produtor de verdade e de produção de verdade. Começarei pelo segundo.

Percebemos em ambas as passagens desta obra de juventude do Estagirita uma constante ao longo de suas investigações e teorizações posteriores sobre o conceito de verdade: conquanto do ponto de vista lógicosemântico seja necessário reconhecer uma simultaneidade entre uma declaração verdadeira e o estado de coisas por ela referido, é igualmente necessário reconhecer que a verdade ou falsidade de qualquer declaração está fundada na existência ou inexistência do estado de coisas ao qual se refere e não o inverso. Em outros termos conceituais, o ser mesmo das declarações e o que convencionamos chamar seu conteúdo semântico, é ontologicamente dependente do ser mesmo dos estados de coisas aos quais podem se referir. Portanto, parece clara a conclusão de que a relação de produção de verdade que intercorre entre os portadores de verdade (as declarações e o seu conteúdo proposicional) e seus respectivos produtores de verdade (os estados de coisas referidos) é uma relação marcada pelo que podemos chamar de correlação entre fundação ontológica e dependência ontológica, pois a relação de fundação é a expressão invertida da relação de dependência, ou seja, X fundamenta ontologicamente $\mathrm{Y}$ se, e somente se, Y depende ontologicamente de $\mathrm{X}^{7}$ Portanto, a relação de produção de verdade proposta por Aristóteles nos trechos analisados pode ser transposta para o vocabulário contemporâneo como uma relação em que os portadores de verdade são ontologicamente dependentes de seus produtores de verdade na exata medida em que estes produtores de verdade fundamentam ontologicamente os portadores de verdade que a eles se referem. Esta correlação de fundação e dependência entre portadores e produtores de verdade é aqui ainda apenas indicada de modo sucinto e sumário. Será apenas na discussão aristotélica do conceito de verdade na Metafísica que tal correlação se tornará mais clara, tal como veremos abaixo.

\footnotetext{
${ }^{7}$ Cf. SCHAFFER, 2008, p. 11; 2009, p. 350-354. Schaffer critica as abordagens tradicionais da relação de produção de verdade a partir dos conceitos de necessidade e de superveniência, postulando que tal relação é essencialmente definivel em suas peculiaridades através da noção de fundação ontológica (ontological grounding). Schaffer remete tal conceito à obra de Aristóteles, ainda que não se detenha na exegese do filósofo antigo. Sobre a ligação entre os conceitos de fundação ontológica e dependência ontológica como conceitos inter-definíveis, veja-se SIMONS, 1987, cap. 8.
} 
A partir dos contextos citados, percebemos que Aristóteles determina os produtores de verdade como estados de coisas (pragmata). Mas como determinar o sentido exato deste conceito? É usual a tradução do termo 'pragma' por 'coisa'. Ackrill o transpõe por 'actual thing'. ${ }^{8}$ Crivelli vale-se de 'state of affair' e 'object'. ${ }^{\text {' }}$

Etimologicamente o termo deriva do verbo 'prattô', ou seja, agir, fazer. O equivalente latino mais próximo seria 'factum' derivado do verbo 'facere'. Assim, em nossa língua o termo gramatical e etimologicamente mais adequado seria 'fato'. Contudo, na ontologia analítica recente, especialmente aquela encontrada no primeiro Wittgenstein, em Russell e em David Armstrong, o conceito de fato recebeu determinações que não podem ser identificadas com o sentido com que Aristóteles usa o termo 'pragma', especialmente por duas razões. A primeira é que a noção de fato é determinada por estes filósofos contemporâneos como algo que corresponde a proposições enquanto entidades abstratas (que Frege chamou de pensamentos). A noção aristotélica de enunciado declarativo não pode ser equiparada com a noção de proposição, tal como o pode o conceito estoico de exprimível ou dizível (lekton). A segunda razão é que Aristóteles claramente não se dispõe, como Russell e Armstrong, a postular algo como fatos negativos (que corresponderiam a proposições negativas), como fica claro por sua recusa tanto da solução platônica do conceito de não ser, tal como encontrada no diálogo Sofista, quanto por sua dura crítica às Ideias.

Mesmo a tradução de 'pragma' por estado de coisas tem de ser explicada à luz dos usos feitos deste termo por Aristóteles. Uma primeira tentativa seria a de considerá-lo como coextensivo com o termo 'to on'. Contudo, isto não parece verdadeiro, uma vez que o Estagirita usa o termo 'pragma' também para designar o que não é (to mê on), como fica claro no exemplo do bode-cervo ou tragélafo, no início do tratado Sobre a interpretação, capítulo 1 (16 a 16-17). De acordo com Aristóteles, este termo significa algo sobre o qual possível fazer declarações verdadeiras (por exemplo, "O tragélafo não é") e declarações falsas (por exemplo, "O tragélafo é"). O termo 'tragélafo' significa um estado de coisas que não existe, designa um não ente, algo que não é o caso no mundo real, de modo análogo a como o termo 'diagonal comensurável' significa um estado de coisas neces-

${ }^{8}$ Cf. ACKRILL, 2002 (1963).

${ }^{9}$ Cf. CRIVELLI, 2005, introdução, esp. p. 4-5, 12-15. 
sariamente não existente, ou seja, que é impossível existir em qualquer momento do tempo. Note-se que grifei o termo 'significa' em ambos os exemplos para que a formulação não nos conduza à falsa noção de que existiriam estados de coisas que não são: o que seria uma contradição flagrante. Os estados de coisas existem ou não existem. Os termos e enunciados podem se referir a ambos. Mas a referência ainda não é suficiente para apresentar o modo como os estados de coisas são produtores de verdade. Somente os estados de coisas existentes são produtores de verdade, como se depreenderá da análise de Metafísica, IX, 10, que será feita abaixo.

Há vários outros trechos de tratados do Organon onde os conceitos de produtores e de produção de verdade estão presentes de modo decisivo. No entanto, mais importante do que fazer uma análise dos mesmos é mostrar que tais conceitos desempenham um papel decisivo dentro da estrutura conceitual da ciência do ser enquanto ser desenvolvida por Aristóteles nos Livros centrais da Metafísica, pois isto mostrará que uma adequada compreensão da concepção aristotélica da verdade como correspondência passa necessariamente por uma investigação sobre o papel dos conceitos de produtores e produção de verdade, uma vez que, para além das obras que compõem o Organon, é nesta obra que encontramos momentos decisivos desta concepção, os quais serão igualmente decisivos para toda a tradição filosófica posterior.

\section{B) ALGUNS ASPECTOS FUNDAMENTAIS DOS PRODUTORES E DA PRODUÇÃO DE VERDADE NA METAFÍSICA}

B.1) Os produtores de verdade e a relação de produção de verdade como exigência implícita na definição de verdade em Metafísica, IV, 7:

Dentro dos textos que compõem a Metafísica, os conceitos de verdade e falsidade constituem, em diversas passagens argumentativas, momentos cruciais de análise da obra. Parece-me que o mais importante desses momentos é a concepção destes conceitos como um dos tipos gerais de significação do conceito de ser (e de não ser), ao lado dos outros tipos, representados pela significação categorial e pela significação modal deste conceito. No que tange aos conceitos de produtores e de produção de verdade, não há dúvida de que o passo mais importante desta obra encontrase no complexo e controverso capítulo 10 do Livro IX. Nele encontramos 
uma determinação da significação veritativa do conceito de ser através da postulação de dois tipos gerais de estados de coisas como produtores de verdade (os estados de coisas compostos e os não-compostos ou simples) para aquelas entidades que Aristóteles, desde as obras do Organon e também na Metafísica, toma como os legítimos portadores de um valor de verdade: os estados mentais com pretensão de verdade e os enunciados declarativos que os exprimem.

Todavia, tal capítulo é controverso não apenas por sua estrutura mesma, mas especialmente por apresentar determinações sobre a significação veritativa do conceito de ser que se contrapõem àquelas apresentadas no capítulo 4 do Livro VI da mesma obra. Jaeger diz que o texto foi inserido na Metafísica de modo ad hoc por Aristóteles ou por um editor, no intuito (malogrado) de fazer uma ligação entre a doutrina da substância sensível encontrada nos Livros VII, VIII e IX (1-9) e a doutrina da substância suprasensível apresentada no XII. ${ }^{10}$ Ross considera o texto como sendo de Aristóteles, mas seu conteúdo pouco teria a ver com o restante do Livro IX, deixando em aberto se está ou não fora de lugar. ${ }^{11}$ Ambas as opiniões, no fundo, baseiam-se na tradicional visão de que a concepção standard de verdade para Aristóteles seria aquela encontrada no Organon e no Sobre a alma, concepção que se reflete claramente no capítulo 4 do Livro VI e que delimita a investigação do conceito de verdade à lógica, à epistemologia e à filosofia da mente, excluindo-o do escopo de investigação da filosofia primeira.

Deixarei de lado a discussão dos problemas referentes à compatibilidade ou à incompatibilidade entre estes dois capítulos (o que nos levaria em outra direção do que aquela pretendida no presente artigo), para sugerir que o capítulo 10 do Livro IX não se correlaciona (quer em continuidade, quer em contradição) com o capítulo 4 do Livro VI, tal como pensam praticamente todos os intérpretes, mas que a determinação da significação veritativa do conceito de ser através da postulação dos tipos de produtores de verdade deve ser tomada como parte própria necessariamente pertencente ao projeto da ciência do ser enquanto ser delineado no Livro IV da Metafísica. Mais especificamente: que o capítulo 10 do Livro IX responde à necessidade de a ciência do ser enquanto ser apresentar-se capaz de mostrar como também a significação veritativa do conceito de ser remete, em última

\footnotetext{
${ }^{10}$ Cf. JAEGER, 1968 (1934), p. 204-205.

11 ROSS, 1970 (1924), vol. II, p. 274.
} 
instância, à significação focal da substância, e não apenas, como já é comum pensar, mostrar como é possível a remissão das significações categorial e modal de ser à significação de ser como substância. Ainda mais diretamente, quero sugerir que as determinações conceituais do capítulo 10 do Livro IX respondem às exigências colocadas pela definição de verdade encontrada no capítulo 7 do Livro IV.

Neste ponto, antes de apresentar minha visão de tal definição, é importante deixar claro que suponho que, no Livro IV, Aristóteles está propondo uma visão ontológica de procedimentos e conceitos de ordem lógico-semântica e epistêmico-mental já existentes em sua obra anterior. Em especial, na sequência dos capítulo 3 a 8 deste Livro, o Estagirita propõe, no delineamento da estrutura geral da ciência do ser enquanto ser, uma interpretação ontológica dos princípios de não contradição e do terceiro excluído, ou seja, tais não são apenas princípios do dizer e do pensar, mas princípios da ordem da realidade mesma, tal como fica manifesto no capítulo 3, onde assume tais princípios como tema da filosofia primeira porque "é evidente que existem em tudo enquanto ente" (1005 a 27). É necessário, assim, que a verdade destes princípios seja de ordem ontológica e não apenas de ordem lógico-semântica e epistêmico-mental. É justamente o projeto delineado no Livro IV da Metafísica que torna necessária a ampliação dos conceitos de verdade e falsidade de modo a que se apliquem não mais apenas a pensamentos com pretensão de verdade e enunciados declarativos, mas também e primeiramente aos estados de coisas que são objeto destes pensamentos e enunciados.

A partir desta visão do estatuto eminentemente ontológico dos princípios primários pode-se fazer uma leitura algo diversa da célebre passagem no início do capítulo 7 em que o mestre do Liceu apresenta a mais famosa versão da definição correspondencial de verdade:

"Mas, com efeito, não é possível haver nada entre <os estados de coisas> contraditórios, mas é necessário afirmar ou negar um <predicado> qualquer [hotioun] de um único [kath'henos] <destes estados de coisas>. E isto é evidente primariamente para quem tenha definido o que <são> o verdadeiro e o falso. De um lado, o dizer não ser [mê einat] o que é [to on] ou <o dizer> ser o que não é [to mê on], 〈é> falso; de outro lado, o <dizer> ser o que é e <o dizer> não ser o que não é, <é> verdadeiro; de modo que aquele que disser 
'ser' ou 'não <ser>' estará dizendo a verdade [alêtheuseı] ou estará dizendo falsidade [pseusetai]."12

Em geral, esta passagem é entendida em termos puramente lógicosemânticos, em grande medida por conta da influência da concepção semântica da verdade elaborada por Tarski, uma vez que o grande pensador polonês toma tal passagem como ponto de partida para elaborar sua visão semântica do conceito de verdade para linguagens formais. Mas há ao menos três aspectos que separam claramente o conteúdo da passagem citada e sua versão semântico-formal: (i) Aristóteles não opera aqui, nem em outros momentos de sua obra, com a distinção entre linguagem-objeto e metalinguagem, distinção imprescindível na concepção tarskiana de verdade; (ii) enquanto a concepção semântica de verdade proposta por Tarski é epistemológica e ontologicamente neutra, a definição apresentada por Aristóteles está claramente comprometida com uma ontologia de substâncias e com uma epistemologia fundacionista e externalista; e (iii) enquanto a concepção semântica de Tarski é elaborada ao nível da lógica de proposições para a partir deste nível ser aplicada à lógica de predicados, a concepção aristotélica se mantém no nível da lógica de predicados.

Por conta destas diferenças, a leitura recente da passagem em termos puramente lógico-semânticos parece-me não apenas contrária à estrutura do trecho mesmo, mas também (senão sobremodo) contrária ao caráter eminentemente ontológico do Livro IV como um todo. Destarte, se estas distinções estão corretas, o trecho, assim como o capítulo, apresenta o princípio do terceiro excluído como uma determinação fundamental não apenas do pensar e do dizer, mas dos estados de coisas que compõem o mundo mesmo que pode ser pensado e dito. Em suma, não há nada entre os enunciados contraditórios porque não há nada entre os estados de coisas contraditórios. Se houvesse algo entre estes, concluirá Aristóteles pouco abaixo (1012 a 5-9), então teria de haver algo além de ser e não ser, o que é absurdo uma vez que estes termos se aplicam a qualquer coisa.

Assumindo tal visão da passagem, importa salientar que o verdadeiro e o falso são valores de verdade primariamente das declarações (das asserções, diríamos em nosso vocabulário atual) e só então dos enunciados declarados. É isso que faz Aristóteles usar as formas verbais gregas 'dizer a verdade'

12 Metafisica, IV, 7, 1011 b 23-28. 
[alêtheuein] e 'dizer a falsidade' [pseudesthar], as quais não têm correlatos diretos em português. Ou seja, o que é primariamente portador de um valor de verdade não é o enunciado, mas sua declaração. Uma declaração predicativa (afirmativa ou negativa) é verdadeira quando assevera como verdadeiro um enunciado que não está em contradição com o estado de coisas referido por ela. Inversamente, uma declaração predicativa (afirmativa ou negativa) é falsa quando assevera como verdadeiro um enunciado que está em contradição com o estado de coisas referido por ela.

Mas esta perspectiva de interpretação permite apresentar um aspecto ainda mais importante do trecho que nunca foi propriamente posto à luz: a necessária suposição de que o verdadeiro e o falso sejam termos coextensivos aos termos ser e não ser. Esta coextensão fica evidente no final do trecho. Se o ser verdadeiro e o ser falso são significações que se aplicam a todos os estados de coisas que podem ser referidos pelas declarações, então eles não podem "recortar" uma região particular do que é ou do que não é, mas têm de ser necessariamente coextensivos com eles. De resto, esta coextensividade é requerida pela tese aristotélica de que o conceito de ser não denota nenhum gênero determinado de coisas.

A coextensão do ser verdadeiro e do ser falso com o ser e o não ser é confirmada logo após o trecho acima citado, agora desde o ponto de vista lógico-semântico e epistêmico:

"Ademais, todo o pensado e apreendido [to dianoêton kai noêton] 〈é> afirmado ou negado pelo pensamento [dianoia] e isto é evidente pela definição <do ser verdadeiro e do ser falso> - quando <declara> de modo verdadeiro ou falso: de um lado, quando compõe [synthề] de certo modo, afirmando ou negando, <declara> de modo verdadeiro [alêtheuet], de outro lado, quando <compõe> de certo modo <declara> de modo falso [pseudeta].$" 13$

Esta coextensão leva Aristóteles necessariamente a conceber o ser verdadeiro e o ser falso como determinações, por assim dizer, transcendentais do ser e do não ser mesmos, determinações que não podem se restringir aos âmbitos do pensar e do declarar, uma vez que estes só podem ser verdadeiros

${ }^{13}$ Metafísica, IV , 7, 1012 a 2-5. 
ou falsos por causa do ser ou não ser dos estados de coisas pensados e ditos. Deste ponto de vista, a definição aristotélica do verdadeiro e do falso pode ser retraduzida assim: o dizer verdadeiro consiste em dizer que o verdadeiro é verdadeiro e que o falso é falso; o dizer falso consiste em dizer que o verdadeiro é falso e que o falso é verdadeiro. Seguindo a sugestão de George Boger, o sentido ontológico do verdadeiro e do falso em Aristóteles coincide, respectivamente, com o sentido das expressões modernas 'o que é o caso' e 'o que não é o caso. ${ }^{14}$ Destarte, o dizer verdadeiro consiste em dizer que o que é o caso é o caso, bem como que o que não é o caso não é o caso; enquanto o dizer falso consiste em dizer que o que é o caso não é o caso e que o que não é o caso é o caso. Ou seja, o dizer verdadeiro ou o dizer falso só podem sê-lo por causa de algo que os torna (makes) verdadeiros ou falsos, e este algo por causa do qual os enunciados e pensamentos tornam-se verdadeiros ou falsos tem de ser verdadeiro (ser o caso) ou ser falso (não ser o caso) em sentido primário.

Por conseguinte, a definição de verdade e falsidade no que tange ao discurso e ao pensamento é ontologicamente dependente de uma significação primária do ser verdadeiro e do ser falso, significação esta que funda o ser verdadeiro ou ser falso das declarações e dos pensamentos que estas exprimem. Em suma: o verdadeiro e o falso no âmbito do discurso e do pensamento necessitam de entidades no mundo que sejam seus produtores de verdade. $\mathrm{O}$ ser verdadeiro em sentido primário como o que é o caso e o ser falso em sentido primário como o que não é o caso conduzem à necessidade de determinar que tipos de estados de coisas podem ou não podem ser o caso. Isto nos conduz à análise da teoria aristotélica dos produtores e da produção de verdade tal como apresentada no capítulo 10 do Livro IX da Metafisica.

B.2) A determinação dos tipos de produtores e de produção de verdade em Metafísica, IX, 10:

Tendo em mente as considerações anteriores, leiamos o início do capítulo 10 do Livro IX:

"Com efeito, posto que o ente e o não ente são ditos, de um lado, segundo as figuras das categorias, e, de outro lado, segundo a potência ou a efetividade destas <figuras $>$ ou $<$ de

${ }^{14} \mathrm{Cf}$. BOGER, 2004, p. 152. 
seus> contrários, e também <segundo> o ente <como> verdadeiro ou falso [em seu sentido mais próprio], o qual, nos estados de coisas, ocorre por <certos itens> estarem unidos ou estarem separados, de modo que, de um lado, diz a verdade aquele que concebe como estando separado o que está separado e como estando unido o que está unido, e, de outro lado, diz o falso aquele que se comporta de modo contrário em relação aos estados de coisas. Mas quando há ou não há o que é dito verdadeiro ou falso?, pois é preciso investigar o que dizemos neste <sentido de ente>. Posto que não é porque concebemos de modo verdadeiro seres tu branco que és branco, mas pelo fato de seres branco <é que> nós, que enunciamos isto, dizemos a verdade." 15

A parte inicial reapresenta a tese sobre as várias significações do conceito de ser. Contudo, diferentemente das outras passagens em que tal enumeração é feita ${ }^{16}$, esta o faz de modo sistemático, excluindo o sentido do ser por concomitância ou acidente. ${ }^{17} \mathrm{~A}$ ordem na enumeração reflete o percurso de investigação presente nos Livros VII, VIII e IX. Vejamos de modo sucinto como isso ocorre. O Livro VII inicia e prossegue sua investigação sobre os vários sentidos de ser postulando como seu âmbito de investigação justamente aquele das figuras das categorias e, dentre elas, a categoria da substância. A expressão 'figuras das categorias' denota aqui, como em outras partes do corpus, as possíveis composições entre categorias nos enunciados predicativos e declarativos. ${ }^{18}$ Mas, ao mesmo tempo, implicitamente aponta

${ }_{15}$ Metafisica, IX, 10, 1051 a 34-b 9. O trecho entre colchetes, ou seja, '[em seu sentido mais próprio]', correspondente à expressão grega 'kyriôtata on', é objeto de grande controvérsia entre os intérpretes. A colocação do mesmo entre colchetes se deve a David Ross em sua edição do texto, indicando o caráter problemático da expressão tanto do ponto de vista filosófico quanto gramatical e filológico (Cf. ROSS, 1970 (1924), vol. 2, p. 274-275). Minha tradução segue a indicação de interpretação feita por Ross, e adotada também em CRIVELLI, 2005, p. 233-237; bem como em MAKIN, 2006, p. 248. Todavia, contrariamente a estes, penso que tal leitura não permite tornar compatíveis o presente capítulo e o capítulo 4 do Livro VI.

${ }^{16}$ Cf. Metafísica, V, 7; Vl, 2.

${ }^{17}$ A exclusão do acidental nesta enumeração pode ser entendida de dois modos, consoante se entenda 0 concomitante do ponto de vista ontológico ou do ponto de vista lógico: entendido do ponto de vista ontológico, não há ciência das propriedades concomitantes a um sujeito, pois elas são contingentes em sentido estrito, ou seja, não ocorrem neste sujeito nem sempre, nem no mais das vezes; entendido do ponto de vista lógico, 0 concomitante é uma predicação de ordem secundária que sempre remeterá a uma predicação em sentido estrito, na qual um predicado é atribuído a uma substância entendida como sujeito de predicação em sentido primário.

${ }^{18}$ Esta é a interpretação da expressão apresentada por TRENDELENBURG, 1846, p. 7-9. 
para os possíveis conjuntos de propriedades que pertencem a um determinado sujeito ontológico, ou seja, as propriedades que podem ser portadas pelas substâncias enquanto suportes de propriedades. Portanto, as figuras das categorias apresentam-se como um conjunto possível de estruturas lógicosemânticas do discurso declarativo que necessariamente se comprometem com estruturas ontológicas do mundo, estruturas sem as quais os enunciados efetivamente formulados que instanciam estas figuras não poderiam ser verdadeiros ou falsos.

Ainda de modo análogo à enumeração citada, os Livros VIII e IX (1-9) investigaram a correlação entre forma e matéria através da correlação entre potência e efetividade das substâncias e de suas possíveis propriedades. A potência e a efetividade são determinações transcendentais de ordem ontológica que justificam as modalidades no discurso e permitem que este descreva a estrutura do processo mesmo em que as substâncias e suas propriedades ocorrem no mundo sensível. A expressão "a potência e a efetividade destas <figuras>", portanto, aponta para o segundo tipo de significação do ser e como ela remete à significação focal do ser, a saber: à substância e às suas propriedades, as quais podem ser expressas nos enunciados predicativos declarativos. A potência e a efetividade constituem a contraparte ontológica dos conceitos modais que intercorrem nas conexões categoriais que perfazem a totalidade do discurso declarativo.

Por fim, dentre as significações do conceito de ser que remetem à significação focal da substância, resta ao Estagirita analisar o ser como verdadeiro e o não ser como falso, tema do capítulo 10 do Livro IX. No mesmo espírito incrustado na enumeração, as determinações de ordem lógico-epistêmica e de ordem ontológica são correlacionadas, sempre fazendo a primeira ordem remeter à segunda, com o que Aristóteles prossegue o modelo de investigação iniciado no Livro IV.

O núcleo do trecho citado, todavia, encontra-se na determinação do ser verdadeiro e do ser falso em sentido primário enquanto o estar unido e o estar separado de certos itens nos estados de coisas. Tal passagem está em homologia com a definição do dizer verdadeiro e do dizer falso em IV, 7, de tal modo que o verdadeiro consiste em declarar como estando separado o que está separado e como estando unido o que está unido, enquanto o falso consiste em declarar como estando unido o que está separado e declarar como estando separado o que está unido. Ou ainda: o dizer verdadeiro consiste em declarar que o que é verdadeiro é verdadeiro e o que é falso é 
falso; enquanto o dizer falso consiste em declarar que o que é verdadeiro é falso e que o que é falso é verdadeiro.

É importante perceber que se antes o ser verdadeiro e o ser falso eram predicados ou propriedades unicamente de certos estados mentais e das declarações que os exprimem, agora eles são predicados ou propriedades primariamente dos estados de coisas referidos pelas crenças e declarações, sendo, portanto, necessário fazer a diferenciação entre o dizer verdadeiro (alêtheuein) e o ser verdadeiro (alêthes), bem como entre o dizer falso (pseudesthai) e o ser falso (pseudes). É possível interpretar a passagem final do texto à luz desta necessária diferenciação, uma vez que ela coloca a questão de apresentar o ser verdadeiro e o ser falso à luz da tese de que é o estado de coisas que é causador da verdade ou falsidade de qualquer declaração. Entretanto, apesar de percebermos aqui um deslocamento do ser verdadeiro e do ser falso para os estados de coisas, o trecho final está de acordo com a intuição básica já presente nas passagens antes analisadas do tratado Categorias, intuição que requer a postulação dos conceitos de produtores e de produção de verdade de modo a fundamentar o pensamento e o discurso na ordem do mundo e não o inverso.

É justamente a evocação desta intuição que motiva a sequência do presente capítulo, onde o Estagirita apresenta o primeiro tipo geral de estados de coisas, estados de coisas que desempenham o papel de produtores de verdade para um primeiro tipo geral de declarações. Vamos ao texto mesmo:

“Se, portanto, de um lado, 〈há> os <itens〉 que sempre estão unidos e que é impossível estarem separados, e, de outro lado, 〈há> os <itens> que estão sempre separados e que é impossível estarem unidos, e também <há> os <itens nos quais> é possível <acontecer> o contrário, <então, nestes três tipos de casos> o ser é o estar unido e o ser uno e o não ser <é> o não estar unido, mas ser múltiplo. Com efeito, acerca dos 〈estados de coisas> possíveis, a mesma opinião e o mesmo enunciado tornam-se verdadeiros e falsos, e é possível, por vezes, dizer o verdadeiro e por vezes dizer o falso; mas acerca dos <estados de coisas> que não podem se comportar de outro modo <os mesmos enunciados e opiniões> não se tornam por vezes verdadeiros e por vezes falsos, mas os 
mesmos <enunciados e opiniões são> sempre verdadeiros e <sempre> falsos."19

Nesta parte do texto, Aristóteles introduz o primeiro tipo geral de estados de coisas que fundam ontologicamente o ser verdadeiro ou ser falso dos estados mentais (aqui denotados como opiniões) e os enunciados declarativos que os exprimem: os estados de coisas compostos. Este tipo se divide em três subtipos de combinações entre os itens que formam qualquer estado de coisas deste tipo, os quais, de modo geral e abstrato, representam todas as possibilidades das configurações categoriais nas declarações implícita ou explicitamente modalizadas. Os itens que compõem qualquer estado de coisas podem nunca estar unidos, sempre estar unidos e por vezes unidos e por vezes separados. Podemos parafrasear isto dizendo que temos três tipos possíveis estados de coisas: (i) aqueles que nunca são o caso (são sempre falsos); (ii) aqueles que sempre são o caso (são sempre verdadeiros); e (iii) aqueles que por vezes são o caso e por vezes não são (são por vezes verdadeiros e por vezes falsos). No primeiro caso, os itens que compõem o estado de coisas estão sempre separados; no segundo caso, os itens que compõem o estado de coisas estão sempre unidos; e, no terceiro caso, os itens que compõem o estado de coisas podem por vezes estar unidos e por vezes separados.

Esta caracterização não nos deve induzir a pensar que existam estados de coisas impossíveis ou negativos. Só existem efetivamente estados de coisas positivos. São eles que nos permitem dizer que tais e tais estados de coisas não existem ou não são o caso, quer em algum momento do tempo, quer em nenhum momento. Isto fica mais claro quando o Estagirita enumera os tipos possíveis de valores de verdade das opiniões e dos enunciados declarados relativamente às possíveis combinações de união e separação entre itens dos estados de coisas.

De um lado, os estados de coisas possíveis ou contingentes ( $t a$ endechomena) são aqueles cujos itens correlacionados podem estar por vezes unidos e por vezes separados. Acerca destes, as mesmas opiniões e os mesmos enunciados podem ser por vezes verdadeiros e por vezes falsos. De outro lado, Aristóteles fala daqueles "estados de coisas que não podem (ta adynata) ser comportar de outro modo”. Tais estados de coisas são primariamente os estados de coisas necessários, aqueles que não podem não existir e que não

${ }^{19}$ Metafisica, IX, 10, 1051 b 9-17. 
podem não ser como efetivamente são. Estes estados de coisas determinam sobre um sujeito qualquer aqueles itens (propriedades) que são condição necessária tanto para sua existência quanto para seu modo de ser.

Com isso, ao mesmo tempo, são determinados por exclusão todos aqueles itens que nunca podem estar unidos a este sujeito. Os estados de coisas impossíveis são aqueles sempre falsos e sobre os quais é sempre falso dizer que são o caso, ou seja, dizer que tais e tais itens estão unidos a um sujeito. Assim, é impossível (sempre falso) que a diagonal de qualquer quadrilátero seja comensurável com qualquer de seus lados, ou seja, nunca podem estar unidos os itens 'ser a diagonal de um quadrilátero' e 'ser comensurável'. Qualquer ocorrência do enunciado "A diagonal é comensurável" é necessariamente falsa não porque há algo como "o não ser comensurável da diagonal", mas porque há o "ser não-comensurável da diagonal". O enunciado "A diagonal é incomensurável” é logicamente equivalente ao enunciado "A diagonal não é comensurável", mas a contrapartida ontológica de tal enunciado não é um estado de coisas negativo, dado que este enunciado pode ser parafraseado no enunciado afirmativo "toda diagonal de um quadrilátero tem um tamanho diferente de qualquer dos lados deste mesmo quadrilátero.”

Haveria ainda muito a ser dito e explicitado sobre esta passagem, mas o essencial consiste em perceber que uma gama virtualmente infinita de opiniões e enunciados são determinados em seu valor de verdade por estas três espécies de estados de coisas, o que parece atender bastante bem a demanda teórica básica de explicar o maior número possível de instâncias particulares através do menor número possível de princípios explanatórios.

Cumpre passar à análise do segundo tipo geral de estados de coisas, aqueles que Aristóteles chama de não-compostos (asyntheta):

"Mas acerca dos <estados de coisas〉 não-compostos, o que são o ser e o não ser, e o verdadeiro e o falso? Pois <tal tipo de estado de coisas> não é composto, de modo a ser, de um lado, quando está unido, e, por outro lado, não ser quando estiver separado, assim como o <ser> a madeira branca ou o <ser>o diâmetro incomensurável. $\mathrm{O}$ verdadeiro e $\mathrm{o}$ falso não existirão aqui do mesmo modo que naqueles <estados de coisas compostos $\rangle$. E assim como não é o mesmo o verdadeiro nestes 〈estados de coisas〉, assim também não <é o mesmo> o ser, mas o verdadeiro ou o falso <acontecem aqui do seguinte 
modo>: de um lado, o verdadeiro <é> o captá-los [thigein] e enunciá-los [fanar] (pois não é o mesmo afirmar [katafasis] e enunciar [fasis] $)$, de outro lado, porém, ignorar [agnoein] 〈é> não captar <este ser simples> (pois não acontece estar enganado [apatêthênar] acerca da quididade, senão por acidente, e de modo similar acerca das substâncias não compostas, pois não acontece estar enganado <acerca de sua quididade>, e todas estão em efetividade, não em potência, pois <se fossem em potência> viriam a ser e se corromperiam, porém o ente por si mesmo não vem a ser nem se corrompe, pois viria a ser a partir de algo. - Portanto, acerca destes <estados de coisas> que são precisamente algo e efetividades não há engano, mas apenas apreensão [noein] ou não <apreensão>; apesar disso, investiga-se sua quididade, <ou seja>, se são de certo modo ou não <são deste modo>)." 20

A primeira coisa a observar nesta passagem consiste no fato de Aristóteles não usar os termos 'estado de coisas' (to pragma) ou 'estados de coisas' (ta pragmata) associados ao conceito de não-composto. Isso pode pôr em dúvida a tradução apresentada, pois poderia ser o caso que o Estagirita tomasse o conceito de estado de coisa como essencialmente composto, não sendo estados de coisas os itens não-compostos. Parece-me, entretanto, que o fato de não usar explicitamente os termos ' to pragma' e ' ta pragmata' neste trecho não é razão suficiente para excluir que o filósofo não esteja mais subentendendo tal conceito no que diz respeito aos itens não-compostos. Portanto, ao menos em princípio, podemos supor com alguma razoabilidade que Aristóteles ainda esteja falando aqui de estados de coisas de um tipo fundamental. Mas a corroboração de tal hipótese depende do prosseguimento da análise do trecho.

Com efeito, a passagem estabelece uma assimetria entre o tipo geral de estado de coisas antes discutido e este. Esta assimetria é estabelecida por meio de um argumento que se vale da lei de transitividade e da lei de contraposição. $\mathrm{O}$ argumento pode ser estruturado do seguinte modo: se o ser ou não ser dos estados de coisas não-compostos é diverso do ser ou não ser dos compostos, e se o ser verdadeiro e o ser falso dos compostos consiste no estar unido ou estar separado dos itens que o compõem, então o ser

${ }^{20}$ Metafisica, IX, 10, 1051 b 17-33. 
verdadeiro e o ser falso dos estados de coisas não-compostos tem de ser diverso daquele que se dá nos estados de coisas compostos.

Mas esta assimetria não significa que tais estados de coisas nãocompostos sejam totalmente distintos dos compostos. Ao contrário, pareceme que devemos interpretar os estados de coisas não-compostos como os constituintes primários dos compostos. Se tal é correto, então os estados de coisas não-compostos não são entidades distintas dos compostos, mas suas partes elementares. Na realidade, Aristóteles parece apontar aqui para aquilo que no Organon e na própria Metafísica é tomado como objeto primário das definições: a quididade. Ora, a quididade e a definição, de acordo como Metafísica, VII, 4, têm vários sentidos, mas são quididade e definição em sentido primário e próprio das substâncias, e especialmente da forma substancial. $\mathrm{O}$ ser das quididades em geral e especificamente das quididades referentes às formas substanciais não tem um não ser a ele oposto. Em paralelo com este modo fundamental de ser, o ser verdadeiro correspondente às quididades e às substâncias consiste no simples fato de existirem sempre em efetividade e serem os elementos primários de qualquer estado de coisas composto, pois não seria possível que os estados de coisas compostos fossem do modo como são (excluindo o modo como não são) se não existissem seus elementos constituintes, os quais não podem deixar de existir, caso contrário nada composto poderia existir.

No caso do ser verdadeiro correspondente ao pensamento e ao discurso que se refere a estes estados de coisas não-compostos, tal consiste na apreensão de sua existência. Não obstante, Aristóteles não estaria falando aqui que temos algum tipo de acesso privilegiado a estas entidades básicas do mundo. Pode se dar o caso de que ignoremos sua existência. Mesmo assim, isso não impede que elas continuem a ser os constituintes elementares dos estados de coisas sobre os quais falamos. De todo modo, o ser verdadeiro do pensamento e do discurso que se referem a estes estados de coisas básicos consiste no saber que existem, sendo então necessário determinar $o$ que são propriamente, determinação que consiste na procura por sua definição. Mas todo enunciado a seu respeito é de outra ordem do que os enunciados predicativos comuns, os quais sempre se estruturam na forma da afirmação ou da negação. Assim, por exemplo, ao falarmos do triângulo, já pressupomos o saber da existência de linhas, ângulos e pontos, mesmo não tendo destes estados de coisas que o compõem uma definição precisa. Em toda declaração sobre estados de coisas compostos podemos estar enganados 
de algum modo, mas ao falarmos destes estados de coisas não podemos estar enganados acerca da existência de seus constituintes elementares.

Em certo sentido, a postulação da verdade primária do estados de coisas não-compostos e da impossibilidade do engano acerca dos mesmos (uma vez que se saiba que existem através dos estados de coisas compostos que deles emergem), é um postulado tanto ontológico, quanto lógico e epistêmico inevitável. Do ponto de vista ontológico, a existência dos estados de coisas não-compostos é condição de possibilidade para a existência ou inexistência dos estados de coisas compostos. Do ponto de vista lógico, os estados de coisas não-compostos preenchem o papel dos nomes próprios básicos, entendidos como designadores rígidos que nos permite pressupor a existência de sujeitos de predicação sobre os quais pode-se formar enunciados verdadeiros ou falsos. Do ponto de vista epistêmico, os estados de coisas nãocompostos correspondem às definições primárias a partir das quais é possível tanto estabelecer encadeamentos de predicações dedutivas quanto estabelecer um ponto de chegada das predicações indutivas.

Dentro do quadro conceitual de sua ontologia formal de modalidades, Aristóteles postula os estados de coisas não-compostos como uma pressuposição inevitável para que o mundo tenha uma ordem complexa e derivada que emerge do ser em sentido primário e simples (as substâncias primeiras em plena efetividade), ser simples e primário ao qual ("idealmente") correspondem na ordem do pensamento e do discurso esquemas conceituais e enunciados básicos que não podem ser falsos, caso contrário estaríamos fadados ou ao regresso infinito na ordem das entidades (uma vez que não haveria entidades básicas) ou à circularidade das explicações (dado que todos os estados de coisas compostos seriam igualmente fundamentais). O modo de existência de estados de coisas compostos, aos quais correspondem enunciados e pensamentos complexos que podem ser verdadeiros ou falsos, já é evidência suficiente para se postular um nível mais simples de existência, inteligibilidade e discursividade, ainda que a compreensão plena deste nível primário possa ser secundária na ordem de nossa existência concreta. Desta perspectiva, a postulação deste nível elementar dos produtores e da produção de verdade encontrado no capítulo 10 do Livro IX, longe de consistir em um texto fora de lugar, pode ser posto em correlação de analogia com as reivindicações de primariedade aduzidas no Livro IV contra os adversários dos princípios de não-contradição, do terceiro excluído e da definição correspondencial de verdade encontradas ao longo do Livro IV da Metafisica. 
Se estas considerações estão corretas, então é possível concluir, em relação aos textos discutidos anteriormente, que, diferentemente da concepção sobre os produtores e a produção de verdade que se pode depreender das passagens de Categorias antes analisadas, a concepção dos produtores e da produção de verdade que se pode extrair tanto de IV, 7, e de IX, 10 da Metafísica mostra a necessidade de se postular não somente uma ordem de dependência ontológica do ser verdadeiro ou ser falso dos pensamentos e enunciados declarativos em relação ao ser verdadeiro ou ser falso (ser o caso ou não ser o caso) dos estados de coisas do mundo, mas também uma ordem de dependência ontológica entre o ser verdadeiro que intercorre entre os estados de coisas compostos e os estados de coisas nãocompostos que os constituem e dos correspondentes pensamentos e enunciados que podem exprimir estes estados de coisas simples. Tal hierarquia na ordem das dependências ontológicas também matiza e torna mais sutil a hierarquia inversa na ordem das fundações ontológicas de nível ao outro. A relação de produção de verdade, assim, mostra-se bastante complexa, mas esta complexidade parece ser "empiricamente mais adequada" à complexidade real que intercorre na significação veritativa do conceito de ser, posto que esta forma de significação não pode ser desvinculada das significações categoriais e modais de ser, sob pena de a metafísica de Aristóteles perder sua integridade conceitual.

Em conclusão geral e, por assim dizer, prospectiva, é possível conjecturar que a teoria dos produtores e da produção de verdade que se pode extrair tanto dos textos do Organon quanto da Metafísica apresenta-se não como um ancestral primitivo e impreciso de uma discussão contemporânea dele distanciada pelo tempo e pelo rigor conceitual, mas como uma fonte de intuições e esquemas conceituais capazes de nos ajudar a analisar de um ponto de vista filosoficamente relevante diversos aspectos da relação entre pensamento, linguagem e realidade, relação que constitui o núcleo da problemática em torno da concepção correspondencial de verdade, a qual pressupõe a análise dos conceitos de produtores de verdade e produção de verdade. Estudada em detalhe, a teoria aristotélica dos produtores e da produção de verdade poderia não ser apenas um tema para a história da filosofia, mas poderia mesmo originar teorizações contemporâneas sobre estes conceitos a partir das intuições e esquemas conceituais elaborados por 
Aristóteles, teorizações que talvez possam apresentar respostas elegantes a vários problemas levantados pelos críticos e adversários destes conceitos. ${ }^{21}$

\section{Referências bibliográficas}

ACKRILL, J. Categories and De interpretatione. Oxford: Clarendon, 2002 (1963). ARMSTRONG, D. A world of states of affairs. Cambridge: Cambridge UP, 1997. . Truth and truthmakers. Cambridge: Cambridge UP, 2004.

BOGER, G. "Aristotle's underlying logic". In: GABBAY, D.; WOODS, J. (eds.). Handbook of the history of logic, vol. 1. Amsterdam: Elsivier, 2004, p. 112-246.

CRIVELLI, P. Aristotle on truth. Oxford: Oxford UP, 2005.

JAEGER, W. Aristotle. Oxford: Clarendon, 1968 (1934).

KÜNNE, W. Conceptions of truth. Oxford: Clarendon, 2003.

MERRICKS, T. Truth and ontology. Oxford: Clarendon, 2007.

MAKIN, S. Aristotle Metaphysics, Book $\Theta$. Oxford: Clarendon, 2006.

MINIO-PALUELlO, L. Aristotelis Categorie et De interpretatione. Oxford: Clarendon, 2008 (1949).

ROSS, D. Aristotle's Metaphysics, 2 vols. Oxford: Clarendon, 1970 (1924).

SCHAFFER, J. "Truthmakers commitments". Philosophical Studies, vol. 141, n. 1 (2008), p. 7-19.

. "On what grounds what". In CHALMERS, D. et alii (eds.) Metametaphysics. Oxford: Clarendon, 2009, p. 347-383.

SIMONS, P. Parts, a study in ontology. Oxford: Oxford UP, 1987.

TREDELENBURG, A. Geschichte der Kategorienlehre. Berlim: Bethge, 1846.

E-MAIL: nazarenoeduardo@gmail.com

RECEBIDO: Outubro/2012

APROVADO: Novembro/2012

${ }^{21}$ Gostaria de agradecer aqui a Lucas Angioni, Raphael Zillig e Inara Zanuzzi por comentários e questões de ordem filosófica e exegética colocados no âmbito de um minicurso sobre o tema ministrado na Unicamp em agosto de 2012. Tais comentários e questões me ajudaram a tornar mais claros diversos pontos tratados no artigo, além de outros que serão tema para outros artigos. 